\title{
Contribución para el perfeccionamiento del diseño, la construcción y la operación de reactores UASB aplicados al tratamiento de aguas residuales urbanas - Parte 6: Calidad del efluente
}

\section{Contribution for improving the design, construction and operation of UASB reactors treating sewage- Part 6: Effluent quality}

- Fecha de entrada: $01 / 08 / 2018$

- Fecha de aprobación: $17 / 09 / 2018$

Paulo Gustavo Sertório de Almeida / Thiago Bressani Ribeiro / Bruno Sidnei da Silva / Lariza dos Santos Azevedo / Carlos Augusto de Lemos Chernicharo (")

DOI: 10.4322/dae.2018.043es

\section{Resumen}

La calidad del efluente de Plantas de Tratamiento de Aguas Residuales (PTARs) que poseen reactores UASB como parte del tratamiento biológico de aguas residuales depende principalmente de aspectos del diseño, la construcción y la operación que permitan la adecuada gestión del lodo anaerobio, así como la adecuada operación de la etapa de postratamiento por procesos aerobios. La presente Nota Técnica expone un contenido complementario a la Parte 3 de esta Colección de Notas Técnicas, en el sentido de discutir el origen de los problemas y las posibles mejoras del diseño, la construcción y la operación de reactores UASB seguidos de una etapa de postratamiento por filtros biológicos percoladores. Son discutidos: i) aspectos de diseño y operación que influyen en la pérdida de sólidos con el efluente anaerobio, incluyendo la influencia del envío de lodo aerobio a los reactores UASB; ii) aspectos asociados a los requisitos de vertido en cuerpos receptores; $\mathrm{y}$ iii) deficiencias en unidades de post-tratamiento por filtros biológicos percoladores. Se presta especial atención a: i) los aspectos de sistematización operacional para el control del lodo con el fin de evitar la pérdida de sólidos con el efluente; ii) la remoción de materia orgánica con el objetivo de cumplir con los límites de vertido; yiii) los factores que pueden influir en el desempeño de los filtros biológicos percoladores post-reactores UASB.

Palabras clave: Mejoría de la calidad del efluente, postratamiento, sistematización operacional.

\section{Abstract}

The effluent quality of sewage treatment plants comprised by UASB reactors essentially depends on design, construction and operational aspects that allow the necessary management of the anaerobic sludge, as well as the appropri-

\footnotetext{
Paulo Gustavo Sertório de Almeida - Ingeniero Civil de la Universidad Federal de Juiz de Fora (UFJF), Brasil. Máster y doctor en Saneamiento, Medio Ambiente y Recursos Hídricos de la Universidad Federal de Minas Gerais (UFMG), Brasil. Miembro del Instituto Nacional de Ciencia y Tecnología en Plantas Sostenibles de Tratamiento de Aguas Residuales Urbanas (INCT ETEs Sustentáveis por sus siglas en portugués).

Thiago Bressani Ribeiro - Ingeniero Ambiental de la Universidad Fundação Mineira de Educação e Cultura (FUMEC), Brasil. Máster en Saneamiento, Medio Ambiente y Recursos Hídricos de la Universidad Federal de Minas Gerais (UFMG), Brasil. Doctorando en Saneamiento de la Universidad de Ghent, Bélgica y de la UFMG, Brasil. Miembro del Instituto Nacional de Ciencia y Tecnología en Plantas Sostenibles de Tratamiento de Aguas Residuales Urbanas (INCT ETEs Sustentáveis por sus siglas en portugués).

Bruno Sidnei da Silva - Ingeniero Ambiental de la Universidad Federal de Santa Catarina (UFSC), Brasil. Master en Ingeniería Hidráulica y Ambiental de la Universidad de São Paulo (USP), Brasil. Ingeniero de la Compañía de Saneamiento del Estado de São Paulo (Sabesp), Brasil.

Lariza dos Santos Azevedo - Ingeniera Ambiental y Sanitaria de la Universidad Federal de Juiz de Fora (UFJF), Brasil. Máster en Saneamiento, Medio Ambiente y Recursos Hídricos de la Universidad Federal de Minas Gerais (UFMG), Brasil. Miembro del Instituto Nacional de Ciencia y Tecnología en Plantas Sostenibles de Tratamiento de Aguas Residuales Urbanas (INCT ETEs Sustentáveis por sus siglas en portugués).

Carlos Augusto de Lemos Chernicharo (*) - Ingeniero Civil de la Universidad Federal de Minas Gerais (UFMG), Brasil. Doctor en Ingeniería Ambiental de la Universidad de Newcastle upon Tyne, UK. Profesor titular del Departamento de Ingeniería Sanitaria y Ambiental de la UFMG, Brasil. Coordinador del Instituto Nacional de Ciencia y Tecnología en Plantas Sostenibles de Tratamiento de Aguas Residuales Urbanas (INCT ETEs Sustentáveis por sus siglas en portugués).).

(*) Dirección para correspondencia: Avenida Antônio Carlos 6.627-Universidade Federal de Minas Gerais - Escola de Engenharia - Departamento de Engenharia Sanitária e Ambiental-Bloco 1. Belo Horizonte, MG. CEP: 31270-901. e-mail: calemosadesa.ufmg.br
} 
ate operation of the aerobic post-treatment step. This Technical Note is a complementary material to Part 3 of these Technical Notes series aiming to present the problems and their respective origins, as well as the possible improvements of design, construction and operation of UASB reactors followed by trickling filters (TF). The discussed topics are: i) design and operation aspects that affect solid washouts in UASB effluent, including the influence of aerobic sludge return, ii) the compliance to discharge standards, and iii) deficiencies related to the post-treatment step. Special attention is given to: i) operational control of the sludge in order to avoid solids washouts; ii) organic matter seeking to comply with discharge standards; and iii) factors influencing the performance of trickling filters following UASB reactors. Keywords: Effluent quality improvement; operational control; post-treatment.

\section{INTRODUCCIÓN}

Conforme a lo discutido en el conjunto de Notas Técnicas (NTs) que componen la presente colección, la calidad del efluente final de reactores UASB es influenciada por aspectos de diseño, construcción y operación, que pueden afectar también la etapa de postratamiento. En particular, el control de la pérdida de sólidos con el efluente anaerobio es un aspecto crucial para el desempeño global del sistema. En la presente NT, se da mayor énfasis a los filtros biológicos percoladores (FBP), por tratarse de la alternativa de postratamiento más utilizada en las Plantas de Tratamiento de Aguas Residuales Urbanas (PTARs) brasileñas que utilizan reactores anaerobios como primera etapa de tratamiento (CHERNICHARO et al. 2018a). Sin embargo, los sistemas de lodo activado (LA) también son contextualizados en esta NT, debido a la importancia del envío de lodo aerobio proveniente de la etapa de postratamiento para espesado y digestión en los reactores UASB.

La sistematización operacional de los reactores UASB, en términos de control de pérdida de sólidos con el efluente, depende en gran medida de decisiones del diseño, por ejemplo: la previsión y detalle de adecuados sistemas de descarte de lodo y de nata. De igual forma, la consistencia entre la producción efectiva de lodo de la PTAR y el dimensionamiento de las unidades de manejo de la fase sólida es un importante factor en el éxito operacional de los sistemas con reactores UASB seguidos de una etapa de postratamiento. En consecuencia, la elaboración e implementación efectiva de protocolos de descarte de lodo y de nata son las etapas de mayor relevancia para la operación exitosa de las unidades que componen la PTAR.

Con respecto a la influencia de la operación de la etapa de postratamiento en la calidad del efluente del reactor UASB y en las unidades de manejo de la fase sólida, a pesar de las ventajas asociadas al envío del lodo aerobio para espesamiento y digestión en los reactores UASB, esta estrategia ha sido señalada como una de las causas de pérdida de sólidos con el efluente.

La presencia excesiva de sólidos en el efluente anaerobio tiende a provocar una mayor resistencia a la transferencia de masa en sistemas con biopelícula, así como la reducción en el tiempo de residencia de la biomasa aerobia en sistemas de lodo activado. En casos extremos, se ha observado la colmatación de medios de soporte de piedra o grava en FBPs debido a una elevación en la carga de sólidos enviada con el efluente anaerobio. En el caso del postratamiento con lodo activado, una pérdida excesiva de sólidos con el efluente de los reactores UASB, asociada a una baja capacidad de descarte o purga de lodo aerobio excedente, se refleja en elevados requisitos de oxígeno en el tanque de aireación y en el consumo de energía.

Aunque el control de la pérdida de sólidos con el efluente anaerobio a partir de un manejo adecuado del lodo es un factor importante para la calidad del efluente de reactores UASB, otros aspectos también son relevantes para cumplir con los límites de vertido. Sobrecargas hidráulicas o picos de caudal debidos al aporte de aguas pluviales o fal- 
las en la operación de estaciones de bombeo son ejemplos de factores que deben ser considerados.

Adicionalmente, la remoción de nitrógeno, fósforo y surfactantes no es esperada en reactores UASB. En este caso, la etapa de postratamiento puede ser necesaria no solamente para la mejora del efluente en términos de concentraciones de materia orgánica sino también para la remoción de esos compuestos. Sin embargo, deficiencias y fallas operacionales en relación a las unidades de postratamiento pueden comprometer el desempeño global del sistema.

Considerando los aspectos anteriormente reportados, la presente NT discute el origen de estos problemas y las posibles soluciones asociadas al diseño, la construcción y la operación de reactores UASB, incluyendo la etapa de postratamiento por FBPs. Considerando que varios aspectos para el perfeccionamiento del diseño y la operación de reactores UASB relacionados con la gestión de la fase sólida fueron abordados en la Parte 3 de esta Colección de NTs (LOBATO et al., 2018), en este documento el enfoque sobre el control del lodo asume un carácter complementario en relación a: i) aspectos de diseño y operación que influyen en la pérdida de sólidos con el efluente anaerobio, considerando el envío de lodo aerobio hacia los reactores UASB; ii) aspectos asociados al incumplimiento de los límites de vertido en cuerpos receptores; y iii) deficiencias en unidades de postratamiento.

\section{ORIGEN Y PROBLEMAS RELACIONADOS A LA PÉRDIDA DE SÓLIDOS EN EL EFLUENTE ANAEROBIO}

\subsection{Exceso de lodo en el interior de los reactores UASB}

Conforme a lo abordado en la Parte 3 de esta colección de NTs (LOBATO et al., 2018), con el fin de evitar la pérdida indeseable de sólidos con al efluente anaerobio, se debe limitar la masa de lodo en el interior del reactor UASB a un valor máximo, el cual depende de la capacidad de re- tención de lodo en el reactor. Además de la masa máxima que debe ser almacenada en el reactor, también debe mantenerse una baja concentración de lodo (sólidos totales - ST) en el punto más elevado del compartimiento de digestión (concentración inferior a 0,5\% ST).

A modo de ejemplo, en la Figura 1a se presentan las masas de lodo y las concentraciones de sólidos sedimentables en el efluente de cuatro reactores UASB de un mismo volumen y que integran una PTAR en escala plena. Al mismo tiempo, en la Figura $1 \mathrm{~b}$ se presentan las concentraciones de lodo (ST - \%) a lo largo de la altura del compartimiento de digestión de esas mismas cuatro unidades. Se observa que todos los reactores tienen una masa de lodo por encima de la máxima recomendada, definida específicamente para los cuatro reactores en el orden de 9.000 kgST (Figura 1a). Adicionalmente, también las concentraciones de lodo en el punto de muestreo más elevado (2,0 m del fondo de los reactores), están por encima de 0,5\% ST (están en el orden de 2,5\% ST - Figura 1b).

Como resultado, se verifica que los cuatro reactores UASB presentan elevadas concentraciones de sólidos sedimentables en el efluente (medianas variando entre 2 e $3 \mathrm{~mL} . \mathrm{L}^{-1}$ - Figura 1a), lo que confirma que esos reactores tienen masas de lodo por encima de sus capacidades de almacenamiento. Cabe resaltar que los reactores UASB operados adecuadamente (sin exceso de lodo) pueden producir efluentes con concentraciones de sólidos sedimentables por debajo de $1 \mathrm{~mL} . \mathrm{L}^{-1}$.

El origen del problema de exceso de lodo se encuentra usualmente relacionado a los siguientes aspectos: i) falta de capacidad de la unidad de deshidratación para recibir el lodo de descarte anaerobio; y/o ii) falta de protocolos sistematizados de descartes. 

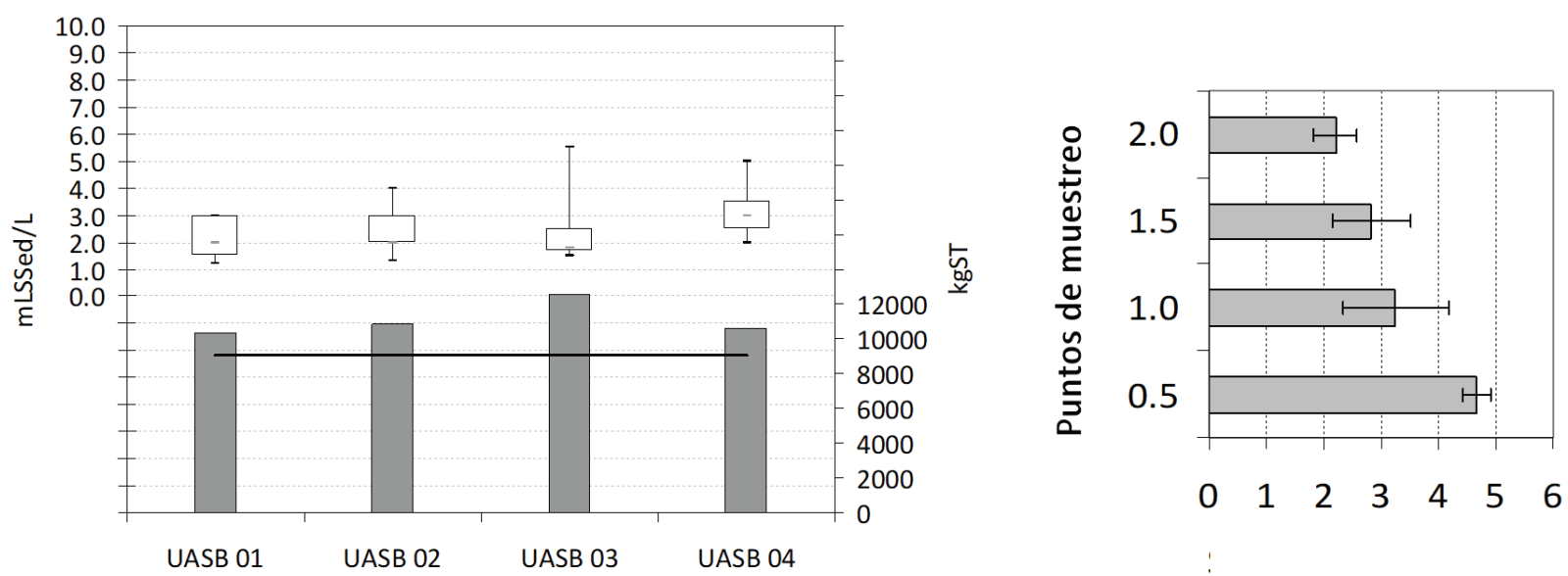

Figura 1 - a) Relación entre la masa de lodo (kgST) en el compartimiento de digestión y la concentración de sólidos sedimentables en el efluente de los reactores UASB (mL.L-1); b) perfil de sólidos a lo largo de la altura del compartimiento de digestión de los reactores UASB.

\subsection{Rutina inadecuada de envío de lodo aerobio a los reactores UASB}

Conforme a lo presentado en la Parte 3 de esta Colección de NTs (LOBATO et al., 2018), el envío de lodo aerobio excedente para espesamiento y digestión en reactores UASB ha sido señalado como una de las causas de pérdida de sólidos en el efluente de estos reactores. Existen varios in formes de operadores de PTARs que relacionan esa pérdida de sólidos a las características del lodo aerobio, pues supuestamente tendría una composición diferente a la del lodo anaerobio y por lo tanto, tiende a flotar y a ser perdido con el efluente del reactor UASB. Por otro lado, estudios rigurosos en dos PTARs en escala plena indicaron buenas características de sedimentación del lodo aerobio enviado a los reactores UASB (CHERNICHARO et al., 2013; FLORIPEZ, 2015) y señalan que la causa de pérdida de sólidos con el efluente anaerobio estaría más bien relacionada a la ausencia de un protocolo adecuado para el manejo del lodo en la PTAR, considerando tanto el descarte de lodo de los reactores UASB como el envío de lodo aerobio de las unidades de pos- tratamiento para espesamiento y digestión hacia los reactores anaerobios.

Esto se ratifica por el hecho de que diversas PTARs presentan serias dificultades en el manejo del lodo, siendo bastante común la presencia de significativos pasivos de lodo (exceso innecesario de lodo) tanto en los reactores UASB como en los sedimentadores secundarios de las unidades de postratamiento. En el caso particular de esas últimas unidades, es común encontrar concentraciones muy elevadas de ST en la etapa de sedimentación secundaria ( 4,0\%), muy por encima de las concentraciones previstas en diseño $(<1,0$ $\%)$. Aunque tal condición parezca improbable, esa realidad ha sido observada recurrentemente, muy posiblemente por la contribución significativa de la fracción de lodo perdida con el efluente anaerobio que llega al sedimentador secundario, principalmente en el caso post-FBPs. Un indicio de que se trata de la acumulación de lodo anaerobio en los sedimentadores secundarios es la nítida producción de gases en la superficie de esas unidades. La Figura 2 ilustra el aspecto de la acumulación excesiva de lodo anaerobio en un sedimentador secundario post-FBP. 

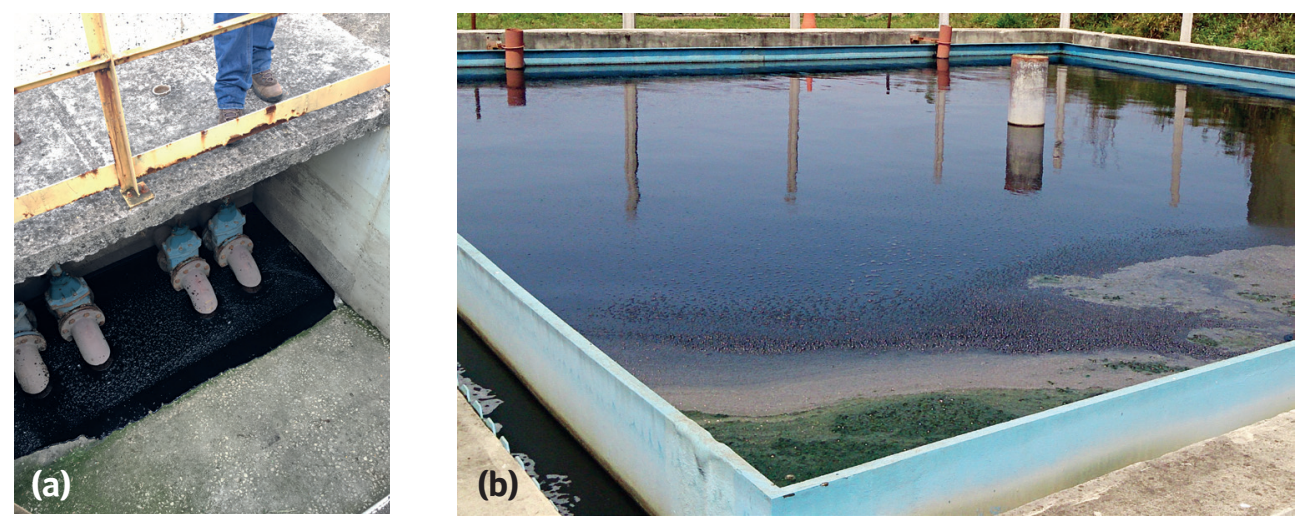

Figura 2 - a) Lodo negro y concentrado descartado de sedimentador secundario de post-FBP; b) lodo flotando y burbujas de gas en la superficie del sedimentador secundario.

Entre las posibles razones para la excesiva acumulación de lodo anaerobio en los sedimentador secundario se pueden citar: i) falta de capacidad instalada en las unidades de deshidratación (mecanizadas o por lecho de secado); ii) largos períodos de mantenimiento de las unidades mecanizadas de deshidratación y/o limpieza de lechos de secado, lo que imposibilita el descarte de lodo excedente; y iii) dificultades logísticas asociadas al envío de lodo para la disposición final.

Frente a lo expuesto, con el fin de eliminar el pasivo de lodo acumulado en los sedimentadores secundarios, los caudales de lodo enviados a los reactores UASB acostumbran ser significativamente mayores (cerca de cuatro veces más elevada) en comparación a los caudales que serían enviados si el lodo en los sedimentadores secundarios tuviera la concentración prevista de diseño, o sea inferior a 1,0\% ST. Adicionalmente, estos caudales de envío de lodo muchas veces son recirculados en lotes (batches) típicamente cortos (de pocas horas), usualmente coincidentes con momentos de caudales afluentes de agua residual elevados, lo que tiende a ocasionar: i) incremento de las velocidades ascensionales en los reactores UASB, lo que a su vez puede provocar mayor pérdida de sólidos con el efluente; $y$ ii) reducción significativa en la capacidad de almacenamiento de lodo en los reactores UASB en función de sobrecarga de sólidos recibida. Por lo tanto, en el caso de que no haya remoción de los pasivos de lodo en los sedimentadores secundarios y en los reactores UASB, este lodo acabará por retornar, de forma cíclica a los FBPs, a los sedimentadores secundarios, y nuevamente a los reactores UASB.

Un ejemplo práctico que demuestra el impacto del envío de lodo aerobio proveniente de sistemas de lodo activado para reactores UASB, como consecuencia del inadecuado manejo de lodo en los reactores anaerobios, se presenta a continuación: a partir de concentraciones de demanda química de oxígeno (DQO) efluentes de un reactor UASB obtenidas para diferentes escenarios operacionales (Figura 3 ), se observa que cuando el lodo del fondo del reactor UASB no fue removido del compartimiento de digestión (condiciones NN y SN), el envío de lodo aerobio para el reactor UASB prácticamente no ejerce influencia en la calidad del efluente anaerobio. Cuando la remoción de lodo del fondo del reactor UASB fue efectuada, hubo incremento de las concentraciones efluentes de DQO aún sin el envío de lodo aerobio (condición NS). Después del envío de lodo aerobio, una mayor variabilidad de las concentraciones de DQO (condición SS) fue observada. Se resalta que las mismas tendencias para concentraciones de sólidos suspendidos totales (SST) fueron observadas. 


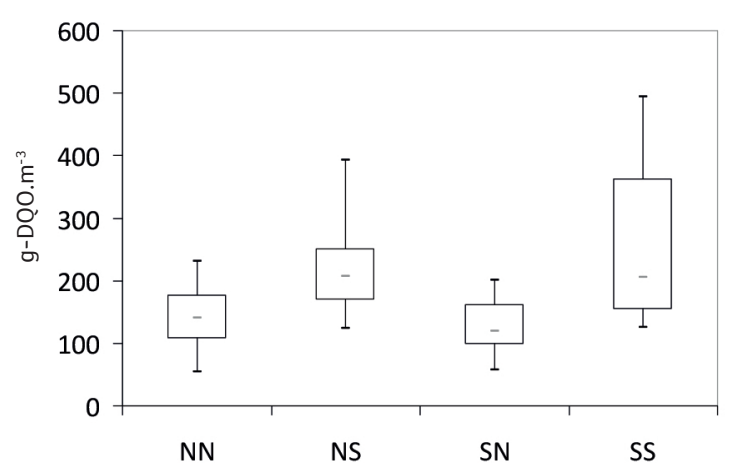

Figura 3 - Influencia del envío de lodo aerobio y descarte de lodo anaerobio del fondo, en las concentraciones efluentes de DQOO y SST del reactor UASB. Las siglas N (no); S (sí) se refieren al envío de lodo aerobio para el reactor UASB y remoción de lodo del fondo del UASB, respectivamente. Fuente: Adaptado de Silva (2018).

En última instancia, el estudio de casos con sistemas UASB seguidos por un sistema de lodo activado muestra que el éxito operacional del envío de lodo aerobio depende de dos aspectos: i) compatibilidad entre criterios operacionales para el control de la edad de lodo en el tanque de aireación y para el envío de lodo aerobio; y ii) sistematización operacional para el descarte de lodo de exceso de reactores UASB con el fin de mantener lodo de mayor sedimentación en el fondo de la unidad.

\subsection{Estrategia de control de la edad de lodo aerobio en sistemas de lodo activado}

La remoción de lodo aerobio excedente para controlar la edad de lodo en los sistemas de lodo activado puede ser realizada por medio de dos alternativas: i) por la remoción de la fracción de lodo activado directamente del tanque de aireación (opción conocida como "descarte hidráulico"); o ii) por la remoción de la fracción de lodo sedimentado en los sedimentadores secundarios. Las dos alternativas presentan ventajas y desventajas en relación al control de edad del lodo en el tanque de aireación y para el envío del lodo aerobio excedente a los reactores UASB para el espesamiento y digestión:
- Envío del lodo aerobio excedente directamente del tanque de aireación. Con el uso de esta alternativa, la concentración del lodo descartado es igual a la concentración de sólidos en el tanque de aireación. En este caso, el control de la edad del lodo es más simple, siendo una razón entre el volumen del reactor (tanque de aireación) y el volumen del lodo removido diariamente. Tomando en cuenta que el lodo aerobio excedente es enviado hacia el reactor UASB a partir del tanque de aireación, el volumen de lodo enviado tiende a ser mayor (cerca del doble), en comparación con la estrategia del envío de lodo aerobio de exceso de los sedimentadores secundarios.

- Envío de la fracción de lodo sedimentado en el fondo de los sedimentadores secundarios. En este caso, el control de la edad del lodo es realizado a partir de la concentración de sólidos en suspensión volátiles en el tanque de aireación y del lodo sedimentado en los sedimentadores secundarios (lodo de recirculación). A pesar de la mayor complejidad para la determinación de la edad de lodo, el lodo excedente es enviado a los reactores UASB a partir de la línea de recirculación de los sedimentadores secundarios y, por lo tanto, en menor volumen debido a la mayor concentración en términos de sólidos.

Por lo tanto, el criterio adoptado para el control de la edad del lodo en el tanque de aireación altera el volumen de lodo enviado a los reactores UASB para su espesamiento y digestión. El envío de mayores volúmenes de lodo a los reactores UASB puede influir en la calidad del efluente anaerobio, principalmente durante los picos de caudal afluente a la PTAR.

Sin embargo, se resalta que para cualquier alternativa adoptada, si el lodo excedente aerobio enviado a los reactores UASB es arrastrado para la superficie y perdido con el efluente del reactor, esto causará un descontrol de la edad del lodo activado porque parte del lodo considerado como retirado del proceso acaba regresando al tanque de aireación. 


\subsection{Fuga de gases del interior del Separador Trifásico (STF) hacia el compartimiento de sedimentación}

Tal como se abordó en la Parte 3 de esta colección de NTs (LOBATO et al., 2018), la ausencia de una remoción sistemática de la capa de nata que se acumula en el interior del separador trifásico puede llevar al espesamiento y solidificación del material acumulado. Esto produce el bloqueo parcial o integral de la interfase de liberación de gases formados durante la digestión anaerobia. De esta forma, el flujo gaseoso que ingresaría a la cámara de gas del separador trifásico tiende a escapar hacia el compartimiento de sedimentación de los reactores UASB, ocasionando el arrastre de sólidos que retornarían al compartimiento de digestión, comprometiendo la calidad del efluente anaerobio en términos de concentración de SST. En sistemas que utilizan unidades de postratamiento, la frecuente sobrecarga de sólidos puede resultar en problemas de obstrucción y colmatación, especialmente en reactores de biomasa adherida (por ejemplo: filtros biológicos percoladores y wetlands). El uso de separadores trifásicos equipados con dispositivos de remoción de nata (por ejemplo: el mecanismo hidrostático propuesto por Lobato et al (2018)) es crucial para la mitigación de la fuga de gases del interior del STF hacia el compartimiento de sedimentación de los reactores UASB.

\subsection{Desnivel de vertedores y acumulación de nata en la superficie de sedimentadores}

El desnivel de los vertedores instalados en las canaletas de salida del efluente anaerobio es un factor importante para la acumulación de nata en la superficie del compartimiento de sedimentación de los reactores UASB. En principio, el desnivel tiende a crear un camino preferencial para el efluente tratado y la acumulación progresiva de nata en zonas hidráulicas muertas (sitios donde son observados menores flujos en los vertedores). En estas zonas muertas, el flujo del líquido parece no garantizar la salida permanente de fracciones particuladas con el efluente, habiendo por lo tanto, acumulación de material flotante (Figura 4).
La acumulación de nata en la superficie de los compartimientos de sedimentación se puede reflejar en el deterioro de la calidad del efluente anaerobio debido a la elevación de las concentraciones de sólidos.

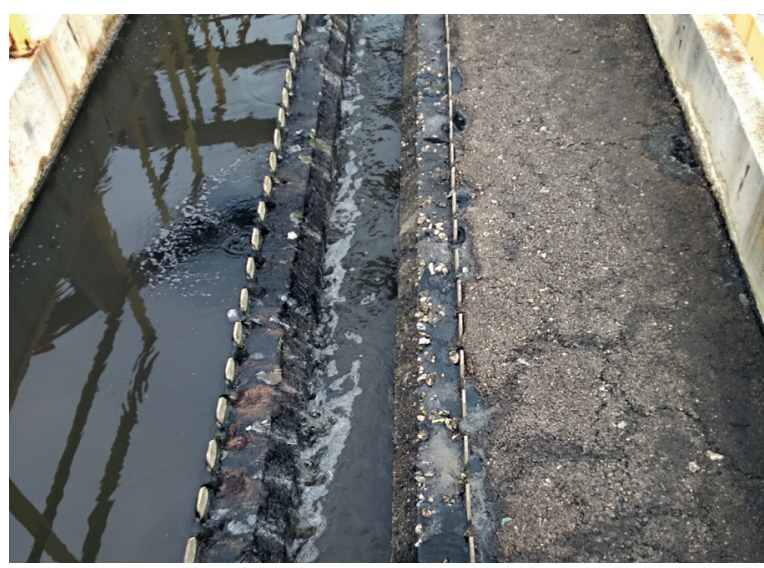

Figura 4 - Acumulación de nata como consecuencia de vertedores desnivelados.

\subsection{Sobrecargas hidráulicas y picos excesivos de caudal}

Sobrecargas hidráulicas y picos excesivos de caudal pueden provocar la expansión excesiva del manto de lodo en la cámara de digestión de los reactores UASB, con la consecuente sobrecarga de los compartimientos de sedimentación y pérdida excesiva de sólidos con el efluente anaerobio. Eventos de sobrecargas hidráulicas y de picos de caudal (gran amplitud de variación entre caudales máximos y mínimos) pueden estar relacionados a cuatro situaciones principales: i) ingreso excesivo de aguas pluviales; ii) caudales de bombeo no consistentes con los caudales promedios y máximos utilizados en el diseño de los reactores anaerobios, conforme lo abordado en la Parte 2 de esta Colección de NTs (BRESSANI-RIBEIRO et al., 2018); iii) contribuciones provenientes de comunidades muy pequeñas (por ejemplo: ciudades con poblaciones inferiores a 2.000 habitantes), que tienden a presentar hidrogramas con picos de caudal con grandes desvíos en relación a su caudal promedio de diseño; y iv) condiciones inadecuadas de envío de lodo aerobio de sedimentadores secundarios 
de la unidad de postratamiento para el espesado y digestión en los reactores UASB, conforme lo discutido anteriormente.

\section{POSIBLES SOLUCIONES RELACIONADAS A LA PÉRDIDA DE SÓLIDOS EN EL EFLUENTE ANAERÓBIO}

\subsection{Existencia de puntos de muestreo de lodo en los reactores UASB}

Conforme a lo detallado en la Parte 3 de esta Colección de NTs (LOBATO et al., 2018), la presencia de puntos de muestreo de lodo adecuadamente posicionados a lo largo de la altura del compartimiento de digestión de reactores UASB es esencial para que el operador tenga mejores condiciones de evaluar si el reactor se encuentra con exceso de lodo (pasivo) en su interior. Entiéndase que la masa de lodo excedente es la diferencia entre la masa de lodo actual en el reactor UASB (determinada a partir de la implementación del perfil de sólidos en el compartimiento de digestión) y la masa de lodo a ser mantenida en el sistema (masa de lodo entre la masa mínima y máxima, conforme lo discutido en Lobato et al., (2018)).

Es de particular interés un muestreo sistemático de lodo en el punto más elevado del compartimiento de digestión, localizado inmediatamente antes del deflector de gases. Según lo destacado por Lobato et al. (2018) en el ítem "Definición de cantidades de lodo a ser mantenidas y a ser descartadas del reactor", la concentración de lodo en ese punto más elevado de muestreo debe estar siempre por debajo de $0,5 \% \mathrm{ST}$.

\subsection{Sistematización de procedimientos y rutinas operacionales para la gestión del lodo}

Además de las recomendaciones para la gestión de lodo producido en los reactores UASB, descritas en la Parte 3 de esta Colección de NTs (LOBATO et al., 2018), los procedimientos y rutinas operacionales para el adecuado manejo de lodo produ- cido en las unidades aerobias de postratamiento (FBPs y lodo activado) deben ser detalladas en los manuales o directrices de operación. Para ello, es imprescindible que se considere en el contrato de diseño la necesidad de elaborar tales documentos, sistematizando la gestión de lodo en la PTAR.

\section{(i) Gestión del lodo y control simultáneo de la calidad del efluente de reactores UASB}

Conforme a lo mencionado anteriormente, la calidad del efluente de los reactores UASB en términos de concentración de sólidos suspendidos está estrictamente asociada a la masa de lodo anaerobio presente en el compartimiento de digestión de tales unidades. Los datos producidos en términos de concentraciones de parámetros físico-químicos deben ser organizadas en hojas de cálculo (por ejemplo: en el programa Microsoft Excel), no solamente para fines de mantenimiento de la base de datos, sino para efectivamente dar sustento al control operacional del sistema de tratamiento de aguas residuales de forma continua. Sin embargo, en muchos casos los datos de perfil de lodo (en términos de sólidos totales y volátiles) no son sistemáticamente utilizados, y su correlación simultánea con datos de calidad del efluente tiende a ser todavía menos recurrente.

Masa de lodo y concentración efluente de sólidos sedimentables. La determinación de la masa de lodo en el compartimiento de digestión es de fundamental importancia para la previsión de una rutina de descarte de lodo de exceso. La frecuente determinación de la concentración de sólidos sedimentables debe ser igualmente considerada con el fin de dar seguimiento a la calidad del efluente del reactor UASB en función del control de la masa de lodo mantenida en el reactor.

Frecuencias recomendadas para la caracterización de la masa de lodo en los reactores UASB y concentraciones efluentes de sólidos sedimentables. El plan de descarte de lodo de los reactores UASB es basado en perfiles de ST implementados a partir del muestreo de lodo a lo largo del compartimiento de di- 
gestión. En principio, el muestreo y la posterior elaboración de perfiles de lodo deberían ser realizadas con base en el crecimiento efectivo (u operacional) del lodo en el interior de los reactores UASB. En este caso, los perfiles de lodo y cuantificación de lodo de exceso (lodo a ser descartado) serían ejecutados en el momento en que la masa estimada de lodo en el compartimiento de digestión exceda ligeramente la masa de lodo recomendada para el período operacional en función de la carga de materia orgánica que ingresa al sistema con el agua residual cruda. Como última instancia, adoptando tal estrategia se garantizará la compatibilidad entre el dimensionamiento de las unidades de deshidratación y la producción de lodo estimada en diseño $\left(\mathrm{Y}_{\text {lodo }}\right)$. La estimación de volúmenes de lodo de deshidratación es presentada en la Parte 3 de esta Colección de NTs (LOBATO et al. 2018).

Se recomienda que el área del laboratorio y el personal de operación de la PTAR sean definidos de modo a proveer las condiciones de implementación de perfiles de ST para cada reactor UASB con la siguiente frecuencia: i) cada 15 días, en el caso de reactores UASB sin recepción de lodo aerobio de la unidad de postratamiento; y ii) un perfil por semana por reactor, en el caso de PTAR con reactores UASB recibiendo lodo aerobio proveniente de los sedimentadores secundarios. Preferiblemente, los muestreos de lodo para la determinación de los perfiles de ST deben ser realizados a lo largo de la altura del compartimiento de digestión y fuera de los horarios de picos de caudal afluente a los reactores (por ejemplo: media mañana o media tarde).

Evidentemente, tanto las unidades de deshidratación de lodo, así como el personal de operación, deben ser definidas con el fin de garantizar la ejecución de las demandas basadas en los resultados de laboratorio para la gestión de la fase sólida. Para el seguimiento de la calidad del efluente se recomienda que los sólidos sedimentables sean medidos por lo menos dos veces por semana, por reactor, considerando preferiblemente muestreos compuestos. Los datos usados para la verificación de la calidad del efluente deben ser los determina- dos más recientemente, en relación al último perfil de concentraciones de ST.

\section{(ii) Control operacional del lodo retenido en} sedimentadores secundarios de FBPs y LA y criterios para el envio de lodo a los reactores UASB

La remoción del lodo excedente de los reactores UASB en cantidad inferior a la producción efectiva es una causa potencial que contribuye para la retención de lodo de baja sedimentabilidad en los reactores UASB. Adicionalmente, criterios inadecuados para el envío de lodo de sedimentadores secundarios hacia los reactores UASB pueden contribuir con la elevación de carga de sólidos enviada a esos reactores y el deterioro de la calidad del efluente anaerobio. En este sentido, además de la consistencia entre la estimación de producción efectiva de lodo con el dimensionamiento de la etapa de deshidratación de lodo, se presentan las siguientes recomendaciones para mejorar la calidad del efluente en sistemas que adoptan el envío de lodo aerobio hacia los reactores UASB:

\section{Preservación de lodo de mejor calidad en el} fondo de los reactores UASB. Conforme lo discutido en detalle en la Parte 3 de esta colección de NTs (LOBATO et al. 2018), el protocolo de descarte de lodo de los reactores UASB debe propiciar la preservación de una fracción significativa de lodo en el fondo (más concentrado), de modo que este pueda actuar como un "filtro" que auxilie en la retención e hidrólisis de sólidos suspendidos presentes en el lodo aerobio enviado a partir de los sedimentadores secundarios de la unidad de postratamiento.

2. Mantenimiento de bajas concentraciones de lodo en la parte superior del compartimiento de digestión de los reactores UASB. Conforme lo discutido anteriormente y también en la Parte 3 de esta Colección de NTs (LOBATO et al. 2018), se debe garantizar que el reactor no esté con exceso de lodo (pasivo) en su interior. La forma más simple de asegurar que no existe exceso de lodo en el 
reactor es por medio de una verificación sistemática del contenido de ST en el punto más elevado del compartimiento de digestión (inmediatamente antes del deflector de gases). La concentración de lodo en estos puntos debe mantenerse siempre por debajo de 0,5\% ST.

\section{Mantenimiento de bajas concentraciones} de lodo en los sedimentadores secundarios. La consistencia entre el crecimiento efectivo de lodo en los reactores UASB y el dimensionamiento del sistema de deshidratación tiende a reducir la carga sobre la etapa de sedimentación secundaria, debido a las menores concentraciones de SST en el efluente anaerobio y postratamiento por FBP o LA. Como consecuencia, la carga de lodo aerobio enviada a los reactores UASB tiende a ser menor, así como las concentraciones de lodo en los sedimentadores secundarios tienden a ser más bajas. Se recomienda que la concentración de lodo en la etapa de sedimentación secundaria no sobrepase $1,0 \% \mathrm{ST}$.

Dos posibles alternativas para solucionar el problema de lodo pasivo en los SS de la PTAR serían: i) incrementar el descarte de lodo de los reactores UASB de modo a no sobrepasar la masa máxima ni la concentración recomendada de lodo en la parte superior del compartimiento de digestión; y ii) remover el lodo pasivo de los SS sin considerar el envío hacia los reactores UASB (por ejemplo: por medio de camiones cisterna).

\section{Establecer el período y caudal de envío de} lodo aerobio para los reactores UASB. Se recomienda que el envío del lodo proveniente de sedimentadores secundarios sea realizado en el período del día en que se observa el menor caudal de aguas residuales urbanas crudas afluente a la PTAR (como regla general, el período de menor caudal afluente ocurre durante la madrugada). En este caso, las bombas de lodo deben ser operadas para el envío de lodo aerobio a lo largo de todo el período de menor caudal. Esta estrategia operacional busca mantener el lodo de menor sedi- mentabilidad en regiones del compartimiento de digestión donde se observa mayor concentración de ST.

\subsection{Verificación del nivel de los vertedores y de} la existencia de fugas de gases del STF

La necesidad de nivelación de vertedores puede ser definida a partir de la observación de caudales irregulares a lo largo de la línea de descarga del efluente anaerobio en las canaletas del efluente. Además de la nivelación de las canaletas, la verificación de velocidades ascensionales y el tiempo de retención del líquido en el compartimiento de digestión y sedimentación, respectivamente, pueden ser importantes aspectos a ser verificados, con el fin de evitar la acumulación de nata. La justificación para tal verificación reside en el hecho de que la mala distribución del líquido entre los reactores UASB también puede ser una causa para la acumulación de nata en la superficie del compartimiento de digestión, según lo mencionado anteriormente.

\subsection{Reducción de picos de caudal efluentes a los reactores}

Conforme a lo señalado en la Parte 1 de esta Colección de NTs (CHERNICHARO et al., 2018b), las posibles mejoras que buscan reducir los impactos generados por los elevados picos de caudal de agua residual afluente a los reactores UASB están relacionadas a: i) utilización de bombas con variadores de velocidad (variadores de frecuencia) o un mínimo de tres bombas, siendo una para relevo y reserva; y ii) implantación de rebalses que efectivamente protejan las unidades subsecuentes del tratamiento en cuanto a sobrecargas hidráulicas. Un mayor detalle de las acciones que pueden ser realizadas es discutido en la Parte 2 de esta Colección de NTs (BRESSANI-RIBEIRO et al., 2018).

\section{ORIGEN Y PROBLEMAS RELACIONADOS AL CUMPLIMIENTO DE LÍMITES DE VERTIDO}

Las legislaciones brasileñas que se ocupan de los límites de vertido del agua residual tratada 
en cuerpos de agua han definido principalmente límites para las concentraciones de materia orgánica. Los límites de vertido referentes a las concentraciones nitrógeno total, fósforo y surfactantes tienden a ser observados en casos específicos, como para el vertido de efluentes en ambientes lénticos, o en el contexto de legislaciones más restrictivas. Como regla general, tales parámetros son considerados para el efluente de una PTAR cuando se tienen cuerpos receptores con estándares de calidad considerablemente restrictivos. El tratamiento anaerobio, a pesar de ejercer un importante papel en la reducción de las cargas orgánicas provenientes del agua residual urbana, usualmente presenta limitaciones para el cumplimiento de los requisitos de vertido en cuerpos receptores. A continuación, se presentan algunos aspectos que dificultan el cumplimiento de los límites de vertido cuando se considera únicamente la etapa anaerobia para la reducción de materia orgánica y remoción de nutrientes y surfactantes.

\subsection{Remoción de materia orgánica}

Los reactores UASB son eficientes en la reducción de la carga orgánica biodegradable del agua residual cruda, razón por la cual los límites de vertido para el cuerpo de agua son potencialmente cumplidos en condiciones en las que se tienen elevadas tasas de dilución del agua residual con el cuerpo receptor. Sin embargo, en el caso de fallas en el diseño, la construcción y la operación de las PTARs, la elevada pérdida de sólidos con el efluente anaerobio es un factor que tiende a perjudicar el cumplimiento de los límites de vertido y el desempeño de la etapa de postratamiento. Cabe resaltar que la baja concentración de oxígeno disuelto en efluentes de reactores UASB también puede ser una limitación, en términos del impacto del vertido del efluente en un cuerpo receptor.

\subsection{Remoción de compuestos nitrogenados}

El cumplimiento de límites de vertido para concentraciones de compuestos nitrogenados únicamente con reactores UASB tiende a ser una opción limitada. Considerando las condiciones operacionales impuestas para la operación de la etapa anaerobia, la asimilación y la amonificación son los procesos metabólicos de mayor relevancia asociados al ciclo del nitrógeno. En este caso, las transformaciones de compuestos nitrogenados prácticamente no resultan en remoción de $\mathrm{N}$-amoniacal o nitrógeno, siendo este un aspecto inherente al proceso de digestión anaerobia, y no propiamente un problema originado en condiciones de diseño, construcción y operación.

\subsection{Remoción de surfactantes}

La composición de diversos productos de limpieza e higiene personal incluyen sustancias tensoactivas o surfactantes, con la finalidad de reducir la tensión superficial del agua. Tales compuestos son precursores de espuma en PTARs o en cursos de agua en los cuales ocurre el vertido de efluentes. La formación de espuma puede ocurrir a partir de la unión de estos compuestos con la superficie de burbujas de aire, debido a eventuales turbulencias presentes a lo largo del proceso de tratamiento o del gradiente hidráulico existente entre el punto de vertido del efluente y el curso de agua. El sulfonato de alquilbenceno lineal (SAL) es el surfactante más utilizado a nivel mundial, y aunque sea biodegradable, su degradación bajo condiciones anaerobias es limitada, del orden de 35\% (DUARTE et al., 2008).

\subsection{Remoción de fósforo}

Le remoción de fósforo $(\mathrm{P})$ en reactores anaerobios es bastante limitada, siendo también esta una limitación inherente al proceso de digestión anaerobia y no propiamente un problema originado en definiciones del diseño, la construcción y la operación. Solamente en condiciones de elevadas tasas de dilución con el cuerpo receptor es 
que los parámetros de calidad de este pueden ser cumplidos. Aunque la etapa de postratamiento sea una opción para el cumplimiento de los estándares de calidad en relación a concentraciones de fósforo (por ejemplo: en sistemas de lodo activado luego del reactor UASB), la remoción biológica de este componente en etapa de postratamiento encuentra dos desafíos: i) relación P/DQO superior a los valores deseados para desempeños elevados; y ii) liberación de fósforo bajo condiciones anaerobias, en el caso de envío de lodo para el espesado y digestión del reactor UASB. Mayores detalles sobre la remoción biológica de fósforo son presentados en Chernicharo et al. (2001) y von Sperling (2017). Cabe resaltar que hay pocos procesos de postratamiento que conducen a elevadas remociones de fósforo.

\subsection{Recepción de efluentes no domésticos}

La recepción de efluentes no domésticos (ENDs) en PTARs que tratan aguas residuales urbanas ha sido una realidad vigente en el contexto brasileño, particularmente en las regiones donde la expansión industrial ocurre de forma más inminente. La contribución de efluentes generados en rellenos sanitarios (lixiviados) también debe ser destacada, ya que dependiendo de la tasa de dilución con el agua residual urbana, pueden ocurrir problemas de toxicidad que impactarían la digestión anaerobia. Adicionalmente, la recepción de lodo de tanques sépticos puede inducir al incremento del coeficiente de producción de lodo en los reactores UASB, lo que tiende a potencializar la pérdida de sólidos en el efluente anaerobio si el proyecto no contempló la recepción de este tipo de contribución. Una discusión más profunda sobre el origen y problemas asociados a la recepción de lixiviado de relleno sanitario de ENDs y de lodo de tanques sépticos en reactores UASB es presentada en la Parte 3 de esta colección de NTs (LOBATO et al., 2018).

\section{POSIBLES MEJORAS RELACIONADAS AL CUMPLIMIENTO DE LÍMITES DE VERTIDO}

La mejora de la calidad del efluente anaerobio por medio de postratamiento es un tema vasto. Hay una serie de sistemas naturales y mecanizados que deben ser consideras, dependiendo de los objetivos del tratamiento, así como de los requisitos necesarios para la implantación y operación (demanda de área, costos, logística de gestión de subproducto, entre otros). Tal como se anticipó en la introducción de esta NT, el presente ítem aborda exclusivamente la utilización de FBPs, por tratarse de la alternativa de postratamiento más utilizada en las PTARs brasileñas que utilizan reactores anaerobios como primera etapa del tratamiento (CHERNICHARO et al. 2018b).

\subsection{Remoción de materia orgánica}

Las experiencias asociadas a la remoción complementaria de materia orgánica en FBPs luego de los reactores UASB se encuentran bien consolidadas. La adopción de FBPs de alta carga con relleno de piedra (cargas orgánicas volumétricas aplicadas en torno de 0,50-1,00 kgDBO. $\mathrm{m}^{-3} \cdot \mathrm{d}^{-1}$ ) permiten obtener eficiencias globales (UASB + FBP) de remoción de materia orgánica usualmente encima de $85 \%$.

\subsection{Remoción de compuestos nitrogenados}

Para los casos en los que la remoción de nitrógeno total es necesaria, los filtros biológicos percoladores rellenos piedra o grava post-reactores UASB son poco eficientes, considerando las condiciones y estrategias operacionales usualmente establecidas. De la misma forma, FBPs de alta carga post-reactores UASB proporcionan una remoción de $\mathrm{N}$-amoniacal poco satisfactoria, en torno de $20 \%$. Para un aumento de la actividad nitrificante en los FBPs (remoción de $\mathrm{N}$-amoniacal arriba de $50 \%$ ) cargas orgánicas volumétricas aplicadas por debajo de $0,24 \mathrm{kgDBO} \cdot \mathrm{m}^{-3} \cdot \mathrm{d}^{-1}$ deben ser utilizadas para el diseño de las unidades. En estos casos, la etapa 
de sedimentación secundaria puede no ser necesaria, considerando los límites de vertido menos restrictivos que son aplicados en algunos países. A partir de la experiencia de períodos importantes en escala plena, el uso de material de relleno de espuma de poliuretano parece ser una alternativa potencial para la remoción de $\mathrm{N}$-amoniacal y $\mathrm{N}$-total en FBPs, post-reactores UASB (ONODERA et al., 2016), sin embargo las experiencias nacionales todavía se limitan a sistemas en escala de demostración (BRESSANI-RIBEIRO et al., 2017).

En contraposición a la lógica de remoción de nutrientes de la fase líquida, se resalta que la utilización de sistemas de postratamiento asociados a la aplicación en el suelo (por ejemplo: fertirrigación y/o recarga de acuíferos) y el reuso del efluente para fines menos nobles (por ejemplo: supresión de polvo en áreas con acceso público restringido) puede reducir la necesidad de remoción de nutrientes. La discusión detallada de tales posibilidades técnicas escapa al alcance de esta NT.

\subsection{Remoción de surfactantes}

Conforme a lo abordado anteriormente, la degradación de surfactantes bajo condiciones anaerobias es limitada. Una alternativa para alcanzar una elevada degradación biológica de surfactantes presentes en efluentes de reactores UASB es la adopción de una tecnología de postratamiento aerobia, una vez que para procesos aerobios se reportan eficiencias de degradación de SAL superiores a $99 \%$ (BRUNNER et al., 1988). Como complemento, una alternativa para minimizar la formación de espuma en cursos de agua está asociada al vertido sumergido del efluente, con el objetivo de reducir condiciones turbulentas precursoras de la formación de espuma.

\subsection{Remoción de fósforo}

Dentro de los procesos que actualmente tienen posibilidad de ser aplicados al postratamiento de efluentes de reactores UASB con el fin de eliminar el fósforo, se destacan los físico-químicos. Aunque la eliminación de fósforo en PTARs puede ocurrir por vía biológica, en los reactores UASB prácticamente toda la materia orgánica fácilmente biodegradable es consumida. Esa elevada remoción de materia orgánica no propicia el establecimiento de condiciones adecuadas para el desarrollo de microorganismos acumuladores de fósforo en la etapa de postratamiento por lodo activado (von SPERLING, 2017).

En lo que se refiere a la remoción físico-química de fósforo, los productos comúnmente utilizados son las sales de aluminio, hierro y calcio. Adicionalmente, polímeros también han sido utilizados con el fin de auxiliar en la floculación. La remoción de fósforo ocurre a partir de la formación de los fosfatos de metales y de calcio, los cuales pueden ser posteriormente removidos por sedimentación, flotación y eventualmente filtración, dependiendo de la concentración efluente deseada.

Cabe resaltar que la dosificación de productos químicos usualmente implica un aumento significativo en la producción de lodo en el sistema, lo que debe ser rigurosamente considerado en el momento de la concepción de la tecnología de tratamiento de agua residual a ser utilizada cuando se tiene el objetivo de remover fósforo. Sin embargo, los procesos físico-químicos son indispensables si la remoción de fósforo es deseada post-reactores UASB. En este caso, tal etapa podría ocurrir entre el reactor biológico (por ejemplo: FBP o lodo activado) y el sedimentador secundario.

\section{ORIGEN Y PROBLEMAS RELACIONADOS AL POSTRATAMIENTO POR FBP}

Distribución del efluente. En caso de que el efluente no sea uniformemente distribuido sobre el medio de soporte, el área húmeda efectiva y el aprovechamiento de área superficial tienden a ser reducidos. Consecuentemente, 
parte del FBP será alimentado con mayores cargas hidráulicas, pudiendo inclusive ser la causa de frecuentes empozamientos por la elevación de carga de sólidos afluente. Dependiendo de lo significativo de la mala distribución del efluente, es posible que el desempeño del sistema sea menor a lo esperado, principalmente debido a la reducción del área superficial utilizada para

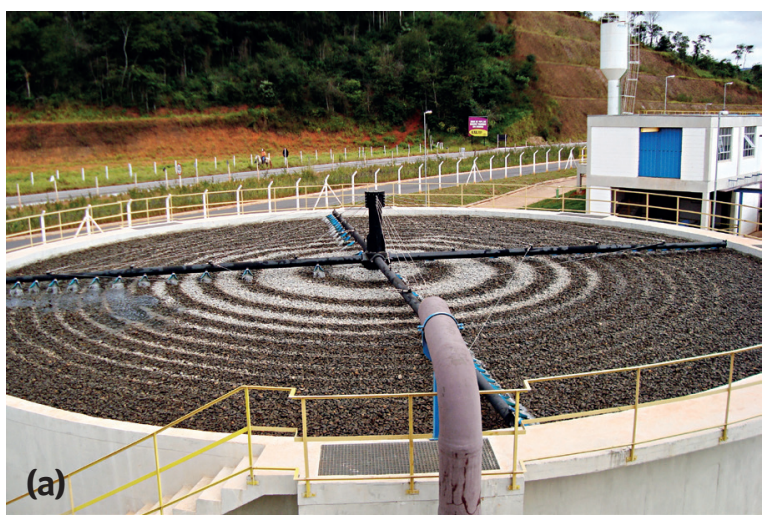

la colonización microbiana y formación del biofilme. La Figura 5 (a-b) presenta un ejemplo de mala distribución del efluente en la parte superior de un FBP relleno con lecho de piedras y con presencia de empozamientos por la colmatación en la superficie del lecho. Esta colmatación puede ser acelerada debido al relleno de FBPs con grava de granulometría inadecuada, tal como será discutido más adelante.

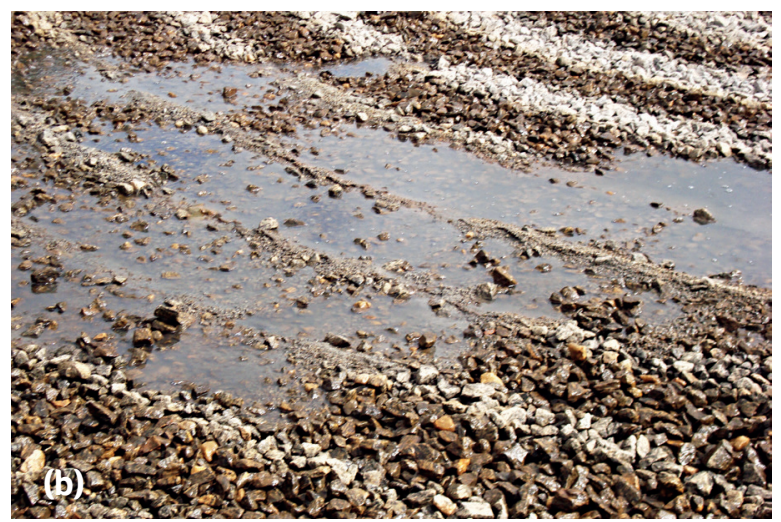

Figura 5 - a) Mala distribución del efluente en la parte superior del filtro biológico percolador post-reactores UASB; b) colmatación de lecho de piedras por elevación de la carga de sólidos.

Cabe resaltar que la obstrucción de orificios/y o atascamiento de los brazos distribuidores pueden también ser una eventual causa de la mala distribución del efluente en la parte superior del FBP (Figura 6). El origen de la obstrucción de orificios es frecuentemente asociado a la elevada pérdida de sólidos en el reactor UASB, debido a fallas en el manejo del lodo. El ingreso de sólidos (basura) en exceso a los reactores UASB por deficiencias en las unidades de tratamiento preliminar también puede ser una causa potencial para tales obstrucciones. El atascamiento de los brazos distribuidores se asocia usualmente a la calidad del equipo y a deficiencias de mantenimiento. Adicionalmente, en momentos de bajo caudal afluente puede comprometerse el número de pasadas o vueltas del brazo previstas en diseño, especialmente para sistemas que no utilizan motores periféricos de accionamiento (situación usual en Brasil).

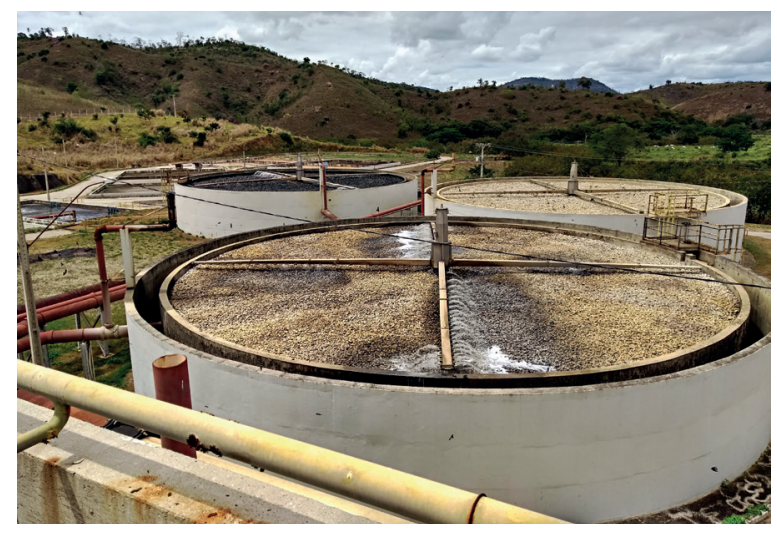

Figura 6 - Distribución desigual de agua residual en FBP como consecuencia de la obstrucción de orificios y/o atascamiento de brazos rotatorios.

Granulometría de lechos de piedra. En el contexto brasileño, los lechos de piedra son frecuentemente utilizados como medio de soporte. En este caso, la colmatación debido a la pérdida excesiva de sólidos con el efluente de reactores UASB se vuelve 
más probable, debido al bajo índice de vacíos del medio de soporte. Las posibilidades de que esto ocurra aumentan cuando la granulometría recomendada (grava con granulometría entre 50-100 $\mathrm{mm}$ de diámetro) no es respetada. En algunos casos, experiencias prácticas señalan la recepción de volúmenes de grava en considerable desacuerdo con las recomendaciones del diseño, incluyendo la presencia de materiales finos como muestra la Figura 7 (a-b).

Esta constatación reside en el hecho de que la grava con granulometría entre $50-100$ mm de diámetro no son frecuentemente utilizadas en la construc- ción civil. Así, el control de la producción de calidad de dicho material tiende a ser menos consistente. Para el suministro de grandes volúmenes de material, como es el caso observado para el relleno de filtros biológicos percoladores en escala plena, las limitaciones en términos de suministro parecen ser todavía más relevantes. Por lo tanto, las dificultades para el control de la calidad en relación a los lechos de piedra como material de relleno y el menor rigor operacional para el control de lodo en reactores UASB son elementos potenciales para el mal funcionamiento de FBPs como etapa de postratamiento.
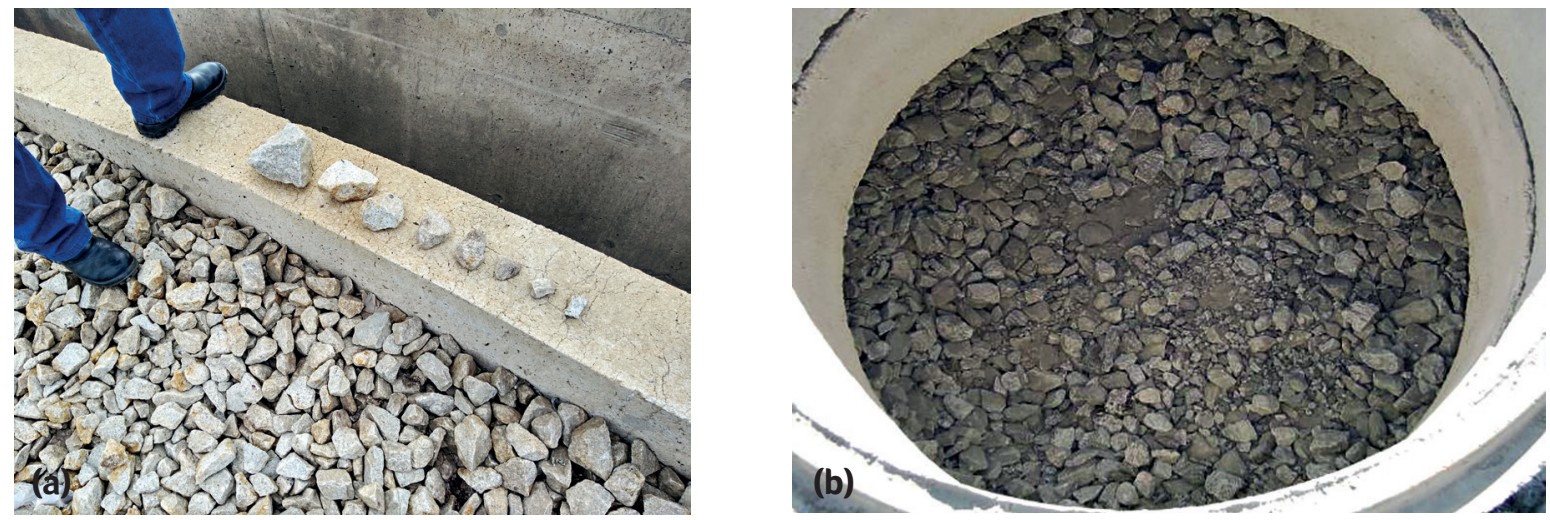

Figura 7 - (a-b) Suministro de grava en desacuerdo con especificaciones del diseño, incluyendo la presencia de materiales finos en la composición del material de relleno.

La colmatación del medio de soporte provoca la creación de caminos preferenciales para el paso del aire y del líquido, imponiendo dificultades en relación al cumplimiento de los requisitos de oxígeno para las reacciones aerobias en la etapa de postratamiento (TCHOBANOUGLOUS et al., 2003). Adicionalmente, la reducción de la actividad nitrificante ha sido observada con el aumento de concentraciones de materiales particulados en el líquido, tanto en estudios de laboratorio (FIGUEROA \& SILVERSTEIN, 1992) como a partir de datos operacionales referentes a sistemas en escala de demostración (ALMEIDA, 2011). En estos casos, la mayor presencia de materia orgánica, la menor disponibilidad de oxígeno y la mayor resistencia a la transferencia de masa explicarían la reducción de la actividad nitrificante en sistemas con biofilme.

Selección del medio de soporte. El desempeño de un FBP post-reactor UASB tiende a estar asociado al medio de soporte utilizado para el relleno del volumen del reactor. En principio, se espera que el uso de medios de soporte con mayor área superficial específica (por ejemplo: medios plásticos) permitan un mejor desempeño del FBP en términos de remoción de materia orgánica y $\mathrm{N}$-amoniacal. Sin embargo, un descuido durante el diseño en relación a la determinación del área húmeda efectiva del medio de soporte, así como 
en relación a las cargas orgánicas aplicadas, pueden causar un menor desempeño de FBPs rellenos con medios de soporte de mayor área superficial específica.

Considerando una condición específica de cargas orgánicas aplicadas $\left(0,25-0,45 \mathrm{kgDBO} \cdot \mathrm{m}^{3} \cdot \mathrm{d}^{-1}\right)$ y tasas de aplicación superficial $\left(10-20 \mathrm{~m}^{3} \cdot \mathrm{m}^{-2} \cdot \mathrm{d}^{-1}\right)$, en un ensayo experimental realizado con el objetivo de seleccionar el medio de soporte para el relleno de FBPs, Almeida (2007) observó que el uso de medios plásticos (área superficial específica entre 80 e $200 \mathrm{~m}^{3} \cdot \mathrm{m}^{-2}$ ) no representa ningún beneficio significativo en la mejora de la calidad del efluente, en comparación con el lecho de piedras para remoción de materia orgánica y $\mathrm{N}$-amoniacal. Las bajas cargas orgánicas aplicadas ciertamente ejercieron una influencia en el desempeño de los FBPs rellenos con medios de soporte de mayor área superficial específica. Adicionalmente, la recirculación continua del efluente no fue considerada, siendo este un aspecto relevante para el aumento de la eficiencia del área húmeda de los medios de soporte, dependiendo de las condiciones operacionales impuestas.

\section{POSIBLES MEJORAS RELACIONADAS AL POSTRATAMIENTO POR FBP}

\subsection{Distribución del afluente en FBPs}

En los casos en que la distribución del efluente sea realizada de forma irregular sobre la superficie de FBP es importante que se realice una revisión del equipo utilizado, con el fin de ajustar la posición y/o revisar el diámetro de los orificios. El objetivo de tales ajustes es proveer una distribución uniforme del efluente en la parte superior de los FBPs y, como consecuencia, promover mejoras en términos del área húmeda efectiva del medio de soporte (Figura 8 (a-b)). Para sistemas rotativos de distribución, se recomienda que tales ajustes consideren el número de pasadas por minuto sobre el medio de soporte, conforme lo definido en diseño. El uso de sistemas motorizados (moto-reductor fijado a uno de los brazos distribuidores y apoyado en la pared externa del FBP) con el fin de mantener la rotación de los brazos, puede ser una alternativa efectiva en los casos en los que el número de pasadas definido en diseño sea incompatible con la energía hidráulica proveniente del efluente anaerobio.
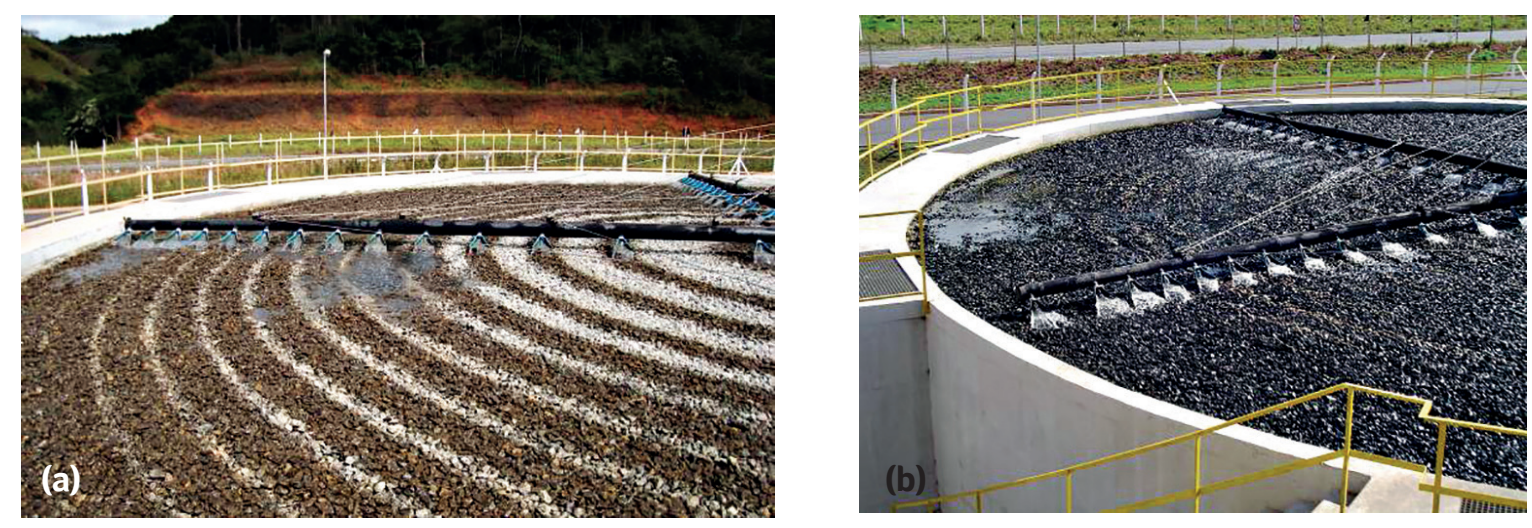

Figura 8 - (a-b) Revisión de la posición de los orificios en los brazos de un distribuidor rotativo. 


\subsection{Medio de soporte para FBPs}

Si las especificaciones del diseño indican el uso de lecho de piedras para el relleno de los FBPs post-reactores UASB, se debe prestar atención al adecuado cumplimiento de las especificaciones y la fiscalización durante la adquisición del material y el relleno de los filtros. Las recomendaciones a seguir deben ser consideradas:

Especificación de diseño. Debe constar en el diseño que el lecho de piedras de granito, gneis o basalto deberá estar compuesto de por lo menos 95\% de material retenido en tamiz con diámetro entre 50-100 mm, sin la posibilidad de admitir material con la presencia de materiales finos en fracciones visualmente excesivas. Esta verificación deberá ser realizada antes del envío del material al sitio de la obra, junto con el proveedor. Piedras "chatas" pero alargadas y de poco espesor deben ser evitadas en cantidad significativas.

Recepción del material en el sitio de las obras. Rigor de la inspección en la recepción del material. Se recomienda que una verificación granulométrica en campo sea realizada por medio de muestreos, con el fin de evitar la necesidad de eventuales substituciones en el medio de relleno, una práctica potencialmente inviable. Los muestreos deberán ser realizados para cada descarga de material en los FBPs. Adicionalmente, en el terreno de la obra deberán disponer de una zona apropiada para el almacenamiento del material, de preferencia un área limpia y pavimentada, de modo a evitar que el material se mezcle con materiales presentes en el sitio (por ejemplo: tierra). Debe evitarse la contaminación del material, principalmente cuando se utilizan cargadores ("backhoe") para transportar el material al interior del FBPs.

Colocación y distribución del material en el interior del FBP. Debe definirse la técnica más apropiada para la colocación y distribución (esparcimiento) del material en el interior del FBP, tomando en cuenta que la forma usual, por medio de la pala de cargadores ha ocasionado varios problemas (por ejemplo: quiebra de piedras y transporte de suelo junto con las piedras). También, la forma de distribuir el material debe ser definida con rigor, con el fin de evitar el uso de máquinas pesadas que puedan causar la quiebra de las piedras y la generación de finos.

Selección del medio de soporte. Como mencionado anteriormente, los FBPs post-reactores UASB en operación en Brasil son usualmente rellenos con lechos de piedras, cuando son diseñados para la remoción de materia orgánica. Sin embargo, i) las dificultades de cumplir las especificaciones granulométricas para sistemas de escala mayor, ii) la necesidad de cumplir los límites de vertido en términos de $\mathrm{N}$-amoniacal, así como iii) el mayor gasto de recursos en estructuras de concreto armado, pueden ser factores limitantes en relación a la aplicabilidad de lecho de piedras como material de relleno. En estos casos, los volúmenes de los reactores tienden a ser bastante elevados, y la reducción de tamaño y robustez de los FBPs pasan a ser aspectos de mayor relevancia para la selección del medio de soporte, a pesar de los menores costos de adquisición de la grava. Esto porque el peso específico de los medios plásticos (30-60 kg.m-3) es significativamente menor al de los lechos de piedra $\left(1.350 \mathrm{~kg} \cdot \mathrm{m}^{-3}\right)$.

En última instancia, el uso de un medio de soporte con mayor área superficial específica puede ser una alternativa potencial para los casos en que:

- la remoción de la materia orgánica no sea el único objetivo de la etapa de postratamiento. En estos casos, el costo de adquisición de un medio de soporte de mayor área superficial y el menor precio unitario puede ser compensando por la reducción del volumen de los reactores; 
- el mayor control de calidad del material de relleno suministrado sea un aspecto de interés.

El control en la producción de medios plásticos tiende a ser mejor que el observado para la producción de grava con granulometría entre 50$100 \mathrm{~mm}$.

\section{CONSIDERACIONES FINALES}

Una vez verificadas las recomendaciones para el diseño, la construcción y la operación de reactores UASB, la calidad del efluente anaerobio requiere el manejo adecuado del lodo en la PTAR, un aspecto que merece todavía más atención en caso de enviar el lodo aerobio proveniente de la etapa de postratamiento a los reactores UASB para su espesamiento y digestión. Cabe resaltar que, independientemente de la tecnología de postratamiento utilizada, en el caso de usar sedimentadores secundarios, la sistematización de la estrategia operacional asociada al envío de lodo hacia los reactores UASB tiende a seguir las mismas recomendaciones observadas en esta NT para el uso de FBPs post-reactores UASB. Adicionalmente, debe prestarse especial atención a los aspectos que producen un efecto perjudicial en la calidad del efluente anaerobio, tal como la acumulación de nata en los compartimentos de sedimentación y separadores trifásicos, así como las sobrecargas hidráulicas que eventualmente puedan elevar las concentraciones de lodo en el compartimiento de sedimentación de los reactores UASB.

Considerando tecnologías simplificadas para el postratamiento de efluentes de reactores UASB, el uso de FBPs rellenos con medios plásticos o basados en espuma de poliuretano tiende a ser una alternativa potencial para mejorar la calidad del efluente final y asegurar el cumplimiento de los límites de vertido en cuerpos receptores. En este caso, la aplicación de tales medios de soporte puede ser una posibilidad en vista de los problemas observados a partir del relleno de volúmenes de reactores con grava.

\section{AGRADECIMIENTOS}

Los autores agradecen recibido del Consejo Nacional de Desarrollo Científico y Tecnológico - CNPq (Conselho Nacional de Desenvolvimento Científico e Tecnológico), de la Coordinación de Mejoramiento de Personal de Nivel Superior - CAPES (Coordenação de Aperfeiçoamento de Pessoal de Nível Superior), de la Fundación de Amparo a la Investigación del Estado de Minas Gerais - FAPEMIG (Fundação de Amparo à Pesquisa do Estado de Minas Gerais) y del Instituto Nacional de Ciencia y Tecnología en Plantas Sostenibles de Tratamiento de Aguas Residuales Urbanas (INCT ETEs Sustentáveis por sus siglas en portugués).

Este trabajo forma parte de la serie de publicaciones del Instituto Nacional de Ciencia y Tecnología en Plantas Sostenibles de Tratamiento de Aguas Residuales Urbanas (INCT ETEs Sustentáveis por sus siglas en portugués).

\section{REFERENCIAS BIBLIOGRÁFICAS}

ALEM SOBRINHO P., JORDÃO E.P. Pós-tratamento de efluentes de reatores anaeróbios - uma análise crítica. Cap. 9. In: Chernicharo C.A.L (coordenador). Pós-tratamento de efluentes de reatores anaeróbios. FINEP/PROSAB, Rio de Janeiro, Brasil, 544 p, 2001.

ALMEIDA, P.G.S. Remoção de matéria orgânica e nitrogênio em filtros biológicos percoladores aplicados ao pós-tratamento de efluentes de reatores UASB. 2011.196p. Tesis (Doctorado en Saneamiento, Medio Ambiente y Recursos Hídricos). - Escuela de Ingeniería, Universidad Federal de Minas Gerais, Belo Horizonte, 2011.

BRESSANI-RIBEIRO, T.; BRANDT, E.M.F.; ALMEIDA, P.G.S.; FLÓREZ, C.A.D. CHERNICHARO, C.A.L. Technological improvements in compact UASB/SBTF systems for decentralized sewage treatment in developing countries. Desalination and Water Treatment. p.01-09, 2017.

BRESSANI-RIBEIRO, T; LOBATO, L.C.S; MELO, V.R.; PEGORINI, E.; NONATO, S.; CHERNICHARO, C.A.L. Contribución para el perfeccionamiento del diseño, la construcción y la operación de reactores UASB aplicados al tratamiento de aguas residuales urbanas - Parte 2: Tratamiento Preliminar. Revista DAE - edición especial, v. 66, n. 214, p. 17-29, 2018.

BRUNNER P.H, CAPRI S., MARCOMINI A., GIGER W. Occurrence and behaviour of linear alkylbenzene sulphonates, nonylphenol, nonylphenol mono-and nonylphenol diethoxylates in sewage and 
sewage sludge treatment. Water Research, v. 22, n. 12, p. 1465$1472,1988$.

CHERNICHARO, C.A.L (coordenador). Pós-tratamento de efluentes de reatores anaeróbios. FINEP/PROSAB, Rio de Janeiro, Brasil, 544 p, 2001.

CHERNICHARO, C.A.L.; VON SPERLING, M.; MONTEIRO, T.A.S. Evaluation of post-treatment alternatives for effluents from the UASB reactors of Onça Sewage Treatment Plant (Belo Horizonte-Brazil). In: VIII Taller y Simposio LAtino Americano sobre Digestion Anaerobia, Punta del Este, Uruguay: IWA, 2005.

CHERNICHARO, C.A.L.; LOBATO, L. C. S., PAVIA JÚNIOR, C. A., BARBOSA, C. A., ALMEIDA, P. G. S., GONÇALVES, T. C. F., VAZ, E., SOUZA, J. R., SILVA, L. R., JUDICE, M. A. M., MORAES, O. J. Secondary sludge return for thickening and digestion in UASB reactors: case study of Onça STP - Brazil. In: XI Taller y Simposio LAtino Americano sobre Digestion Anaerobia, La Havana, Cuba: IWA, 2013.

CHERNICHARO, C.A.L.; BRESSANI-RIBEIRO, T.; GARCIA, G.B.; LERMONTOV, A.; PEREIRA, C.B.; PLATZER, C.J.; POSSETTI, G.R.C.; LEITES, M.A.L.; ROSSETO, R. Panorama do tratamento de esgoto sanitário nas regiões Sul, Sudeste e Centro-Oeste do Brasil: tecnologias mais empregadas. Revista DAE, v. 66, n. 213, p. 5-19, 2018a.

CHERNICHARO, C.A.L; BRESSANI-RIBEIRO, T; PEGORINI, E.; POSSETTI, G.R.C.; MIKI, M. K.; NONATO, S. Contribución para el perfeccionamiento del diseño, la construcción y la operación de reactores UASB aplicados al tratamiento de aguas residuales urbanas - Parte 1: Temas de Interés. Revista DAE - edición especial, v. 66 , n. 214, p. $5-16,2018 b$.

DUARTE, I. C. S., OLIVEIRA, L. L., SAAVEDRA, N. K. D., FANTINATTI-GARBOGGINI, F., OLIVEIRA, V. M., VARESCHE, M. B. A., Evaluation of the microbial diversity in a horizontal-flow anaerobic immobilized biomass reactor treating linear alkylbenzene sulfonate. Biodegradation, v. 19, n. 3, p. 375-385, 2008.

FIGUEROA, L.; SILVERSTEIN, J. The effect of particulate organic matter on biofilm nitrification. Water Environment Research. v. 64, p 728, 1992.

GONÇALVES, T.C.F. Avaliação da prática de retorno de lodo secundário sobre o desempenho de reatores UASB em escala plena: estudo de caso da ETE Laboreaux, Itabira/MG. Disertación (Maestría en Saneamiento, Medio Ambiente y Recursos Hídrcos).
Escuela de Ingeniería, Universidad Federal de Minas Gerais, Belo Horizonte, 2015.

LOBATO, L.C.S.; BRESSANI-RIBEIRO, T.B.; SILVA, B.S.; DIAS-FLÓREZ C.A; NEVES, P.N.P.; CHERNICHARO, C.A.L. Contribución para el perfeccionamiento del diseño, la construcción y la operación de reactores UASB aplicados al tratamiento de aguas residuales urbanas - Parte 3: Gestión del lodo y la nata. Revista DAE - edición especial, v. 66, n. 214, p. 30-55, 2018.

ONODERA, T.; OKUBO, T; UEMURA, S.; YAMAGUCHI, T.; OHASHI, A.; HARADA, $H$. Long-term performance evaluation of down-flow hanging sponge reactor regarding nitrification in a full-scale experiment in India. Bioresource Technology. 204. p. 177-184, 2016.

POSSETTI, G. R. C., RIETOW, J.C.; COSTA, F.J.O.G.; WAGNER, L.G.; LOBATO, L. C. S., BRESSANI-RIBEIRO, MELO, D. F, REIS, J.A, CHERNICHARO, C. A. L. Contribución para el perfeccionamiento del diseño, la construcción y la operación de reactores UASB aplicados al tratamiento de aguas residuales urbanas - Parte 5: Biogás y emisiones fugitivas de metano. Revista DAE - edición especial, v. 66, n. 214, p. 73-89, 2018

SILVA, B.S. Desempenho de Reator UASB em escala plena no tratamento de esgoto sanitário e lodo ativado em excesso do pós-tratamento. Disertación (Maestría en Ingeniería Hidráulica) - Escuela Politécnica da USP, Universidad de São Paulo, São Paulo, 2018.

TANDUKAR, M.; OHASHI, A.; HARADA, H. Performance comparison of a pilot-scale UASB and DHS system and activated sludge process for the treatment of municipal wastewater. Water Research. v. 41, n. 12, p. 2697-2705, 2007.

TCHOBANOGLOUS, G.; BURTON, F.; STENSEL, H. Wastewater engineering: treatment, and reuse. New York: McGraw-Hill, 4th edición., 2003, 1819 p.

VON SPERLING. M. Lodos Ativados. $2^{\mathrm{a}}$ ed. Belo Horizonte: Departamento de Engenharia Sanitária e Ambiental. Universidade Federal de Minas Gerais,, 2002. 428 p. (Princípios do tratamento biológico de águas residuárias, v4).

VON SPERLING. M. Introdução à qualidade das águas e ao tratamento de esgotos. $4^{\mathrm{a}}$ edición. Belo Horizonte: Departamento de Engenharia Sanitária e Ambiental. Universidade Federal de Minas Gerais, 2017. 452 p. (Princípios do tratamento biológico de águas residuárias, $\mathrm{v} 1$ ). 